\title{
Infected hip prosthesis in patient with suspected Covid-19 infection
}

\author{
A. Cosentino* (D), G. Odorizzi and W. Berger
}

\begin{abstract}
Background: Infections following arthroplasty are one of the major risks during this type of surgery. Moreover, the outbreak of coronavirus disease 2019 (COVID-19), caused by SARS-CoV-2 (Severe Acute Respiratory Syndrome CoronaVirus Disease 2), has developed into an unprecedented pandemic, posing enormous pressure on health-care providers around the world.

Case presentation: Four and half years after right hip arthroplasty, the patient came back to our attention with pain at the same hip. The instrumental examinations showed signs of cup detachment. After carefully analyzing the case, we decided to perform a sterile aspiration of the hip in the operating room under C-arm fluoroscopy. Microbiological examinations showed positivity for E. coli. The patient underwent surgery by which the prosthesis was removed and a spacer was implanted. A therapy with Cefotaxim $2 \mathrm{~g}$ three times a day for 6 weeks was then set, and then a total arthroplasty was performed. During this period, the COVID-19 pandemic occurred and therefore the patient received nasal-throat swabbing two times, and both yielded negative results. However, 1 week after the final surgery, his respiratory conditions deteriorated and chest X-ray and CT scan showed images of ground-glass opacification patterns (GGO). Due to the clinical symptoms and the characteristic images of the instrumental examinations, the patient was transferred to an observation ward. Thereafter, two more swab tests gave negative results. The patient was then transferred to the ward for patients with typical symptoms of COVID-19 but with negative swab tests for 2 weeks and was subsequently discharged home.

Conclusion: The purpose of this case report was to point out the correct treatment of a PJI after the outbreak of COVID-19. Despite the ongoing COVID-19 pandemic, the guidelines in the case of periprosthetic hip infection further confirmed the correct management of the patient.
\end{abstract}

Keywords: Prosthetic joint infection, Hip infection, COVID-19 pandemic

\section{Background}

Knee and hip replacements are two most commonly performed elective operations. For most of the patients, joint replacement relieves pain and helps them to live more fulfilling and active lives. Nonetheless, no surgical procedure is without risks. A small percentage of patients undergoing hip or knee replacement (roughly about 1 in 100) may develop infection after the operation. Joint replacement infections may occur in the wound or deep around the artificial implants.
A new coronavirus disease, known as Severe Acute Respiratory Syndrome Coronavirus 2 (SARS-CoV-2) causing coronavirus disease 2019 (COVID-19), hit in December 2019 [1]. On March 11th 2020, the World Health Organization (WHO) declared the disease a pandemic. By then, more than 118,000 individuals were infected in 113 countries and regions. In Italy, at the same date, there were 12,462 cases of infection and 827 deaths in total. At the time of the preparation of this report, the number of infected individuals had increased to $>1.2$ million worldwide. COVID19 has quickly become a global threat to public health.

\footnotetext{
* Correspondence: andrea.cosentino@sabes.it

F. Tappeiner Hospital, via Rossini 5, 39012, Meran, BZ, Italy
}

(c) The Author(s). 2021 Open Access This article is licensed under a Creative Commons Attribution 4.0 International License, which permits use, sharing, adaptation, distribution and reproduction in any medium or format, as long as you give appropriate credit to the original author(s) and the source, provide a link to the Creative Commons licence, and indicate if changes were made. The images or other third party material in this article are included in the article's Creative Commons licence, unless indicated otherwise in a credit line to the material. If material is not included in the article's Creative Commons licence and your intended use is not permitted by statutory regulation or exceeds the permitted use, you will need to obtain permission directly from the copyright holder. To view a copy of this licence, visit http://creativecommons.org/licenses/by/4.0/. 


\section{Case presentation}

The patient presented himself in our orthopedic clinic 4 years after the implantation of a right hip total prosthesis. The patient was 78 years old, with a history of stage IIIA B cell lymphoma in remission. He had been limping with severe pain for about 2 months, walking with crutches, with an about $2-\mathrm{cm}$ difference in the lower limbs. Blood tests showed $11.4 \times 1000 / \mu \mathrm{L}$ leukocytes, CRP at $7.53 \mathrm{mg} / \mathrm{dL}$ and ESR at $84 \mathrm{~mm} / 1 \mathrm{~h}$. X-rays and CT scans showed signs of loosening of the prosthesis towards the pelvis. (Fig. 1).

Before performing a revision, we decided to make a sterile puncture in the operating room under $\mathrm{C}$-arm fluoroscopic control. While waiting for the result of the antibiogram, the patient was treated with an empirical antibiotic therapy. After finding the presence of $E$. coli, the patient was treated with Cefotaxim $2 \mathrm{~g}$ three times per day for 6 weeks.

Then, we decided to remove the implanted prosthesis and to substitute with antibiotic-impregnated cement spacers (Gentamycin and Vancomycin). The femoral stem, the acetabular component and swabs of the muscular fascia and synovial joint fluid were sent to microbiological laboratory for further analysis and the test did not reveal growth of any germ. For this reason, after adequate monitoring of the patient's general condition, he was discharged with an oral antibiotic therapy prescribed and full weight bearing, since the pain was tolerable. (Fig. 2).

According to guidelines, the patient should have received the implantation of the final prosthesis after 6 weeks. However, during the same period, the COVID-19 pandemic occurred and, therefore, in order to plan the definitive operation, it was necessary to contact the hospital's Task Force, which allowed it only 9 weeks after the spacer placement [2-4].

After implantation of the final prosthesis (Acetabular Component 62, Delta TT Company Lima Corporate and two screws $6.5 \mathrm{~mm}$, Stem 12 LCU Company Link, small head $36 \mathrm{~mm}$ Ceramic), the postoperative course was uneventful, and the patient remained asymptomatic, except for a mild anemia, which was treated with Ferric sodium gluconate for 1 week. The postoperative prophylaxis of the infection included a double antibiotic protocol with Cefotaxim $2 \mathrm{~g}$ three times per day and Rifampicin $600 \mathrm{mg}$ once in the evening for the following 8 weeks. (Fig. 3).

During his second hospital stay, two nasal-pharyngeal swab tests were performed for COVID-19, both being negative. The patient was asymptomatic for the first postoperative week. However, while the patient was in our department on the eighth postoperative day, after a sudden worsening of the respiratory symptoms with low oxygen saturation $\left(\mathrm{SpO}_{2} 87 \%\right)$ and severe respiratory distress, an emergency chest X-ray and then a CT scan were performed, and they showed no evidence of pulmonary embolism but revealed multiple areas of ground-glass opacification (GGO) (Fig. 4).

The wound looked normal without signs of infections or dehiscence and there was no swelling or hematoma on the operated hip. We decided to perform a COVID19 rapid test, which showed that patient was positive for COVID-19 IgM.

According to the literature $[5,6]$, there are no defined radiological criteria to distinguish between a pulmonary embolism and a Sars Cov-2 Infection. Moreover, pulmonary embolism (PE) is seen in a high frequency in hospital-treated patients with COVID-19, with an incidence of $30 \%$.

At this time, we had to decide where we had to transfer our patients. As part of a Health Care Company made by 7 Hospitals, the designated Task Force decided to divide the Patients into two subtypes:

1. Patient who tested positive for COVID-19 (Swab test) and had clinical symptoms and/or radiological evidence of COVID-19 Disease;

2. Patient whose results of COVID-19 Swabs were negative but had clinical symptoms or radiological evidence for COVID-19 Disease.

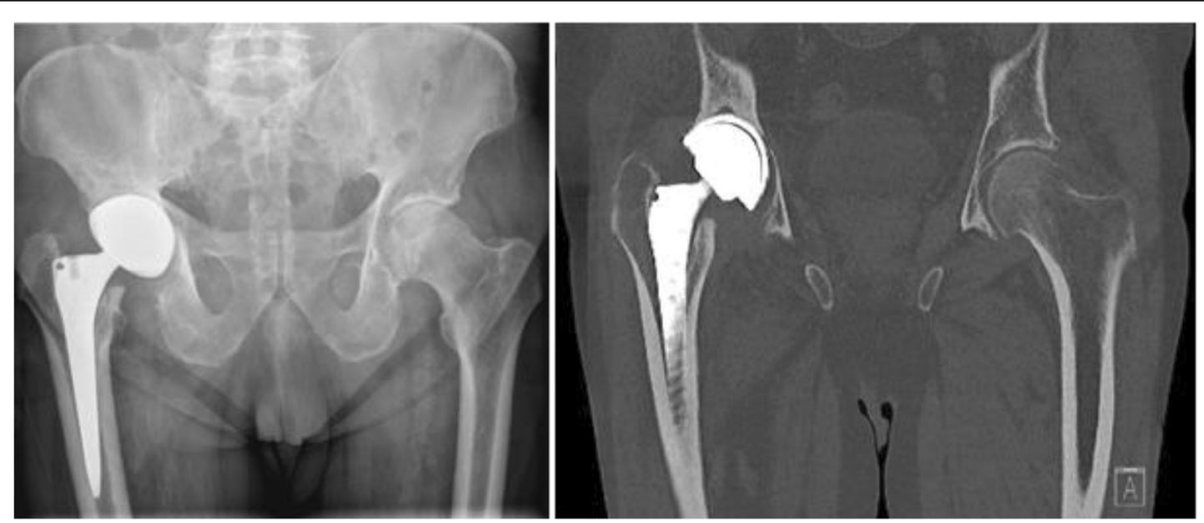

Fig. 1 A-P X-Ray and CT-Scans showed the loosening of the prosthesis 


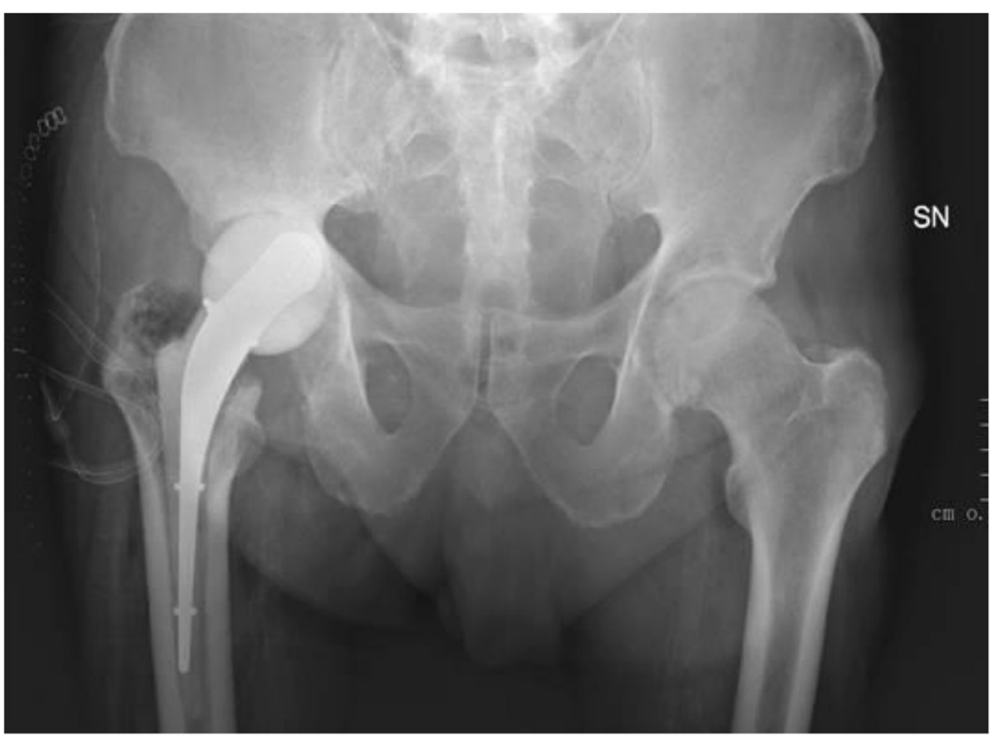

Fig. 2 Removal of the prosthesis and implant of the spacer

The two different groups were treated similarly but in different isolation departments.

Therefore, the patient was transferred to the second one, waiting for further swab tests and further treatment. One week later, after the resolution of the pulmonary symptoms, the patient was finally discharged home.

Two subsequent check-ups were carried out 6 and 10 weeks after surgery, with the first one including X-ray examination. In both examinations, the patient did not report pain, the wound was dry and clean, the mobility was good and the radiography demonstrated an excellent position of the prosthesis without signs of detachment.
Blood tests were consistently normal, with stable CRP level.

\section{Discussion}

In order to reach the final diagnosis, all the steps required by the literature [7] were taken, including: the pre-operative anamnestic and laboratory evaluation, the arthrocentesis, the two-step revision and antibiotic therapy for 6 weeks, adapted on the basis of antibiogram [8].

Treatment depends on the stage of infection and is based on the classification published by Coventry in

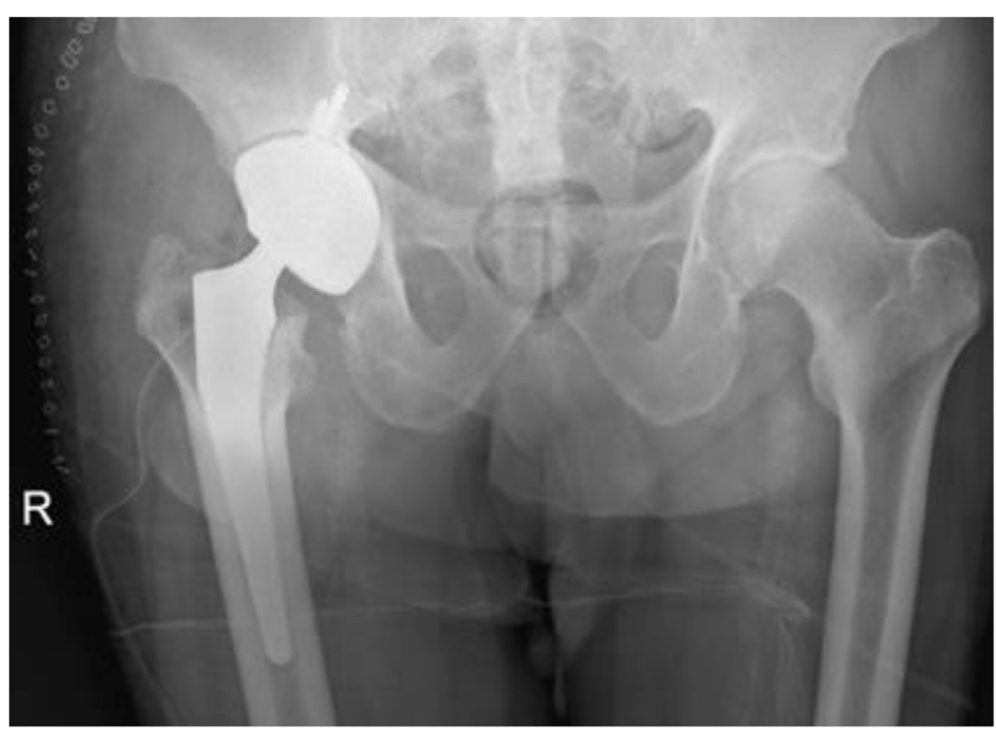

Fig. 3 Definitive prosthesis after 9 weeks 


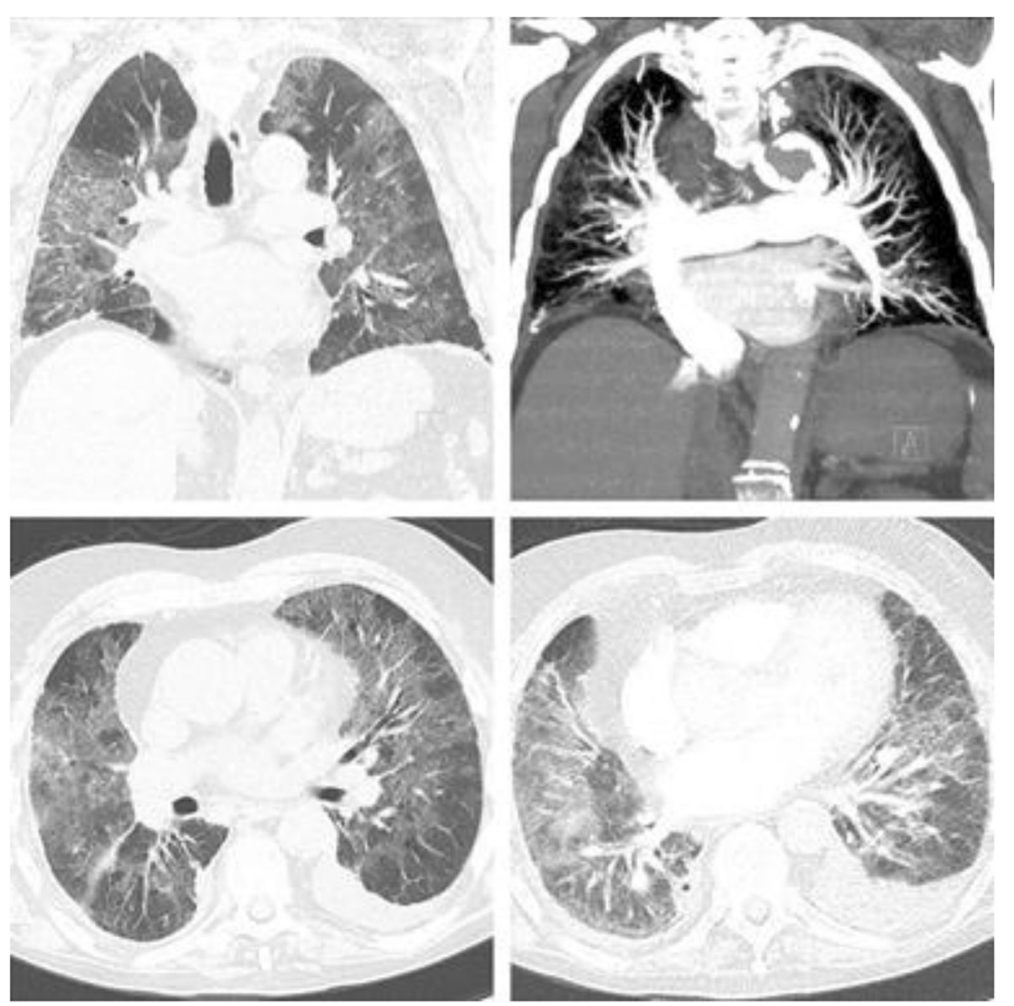

Fig. 4 Thorax CT-Scan showed multiple areas of ground-glass opacification

1975 with the modification by Tsukayama [9]: Stage I infection occurs acutely within 6 weeks after implantation; Stage II infection refers to delayed chronic presentations; Stage III infection takes place in a previously wellfunctioning joint replacement; Stage IV infection is unexpected positive culture results in what was thought to be an aseptic revision.

According to the guidelines, the therapeutic scheme in periprosthetic infections for the removal of the implant and the subsequent definitive prosthesis placement is of one or two stages. The last one is considered to be the gold standard with an eradication rate greater than $90 \%[1,10]$.

\section{Conclusion}

The purpose of this case report is to point out the correct treatment of PJI, especially during this pandemic, as evidenced in a patient who developed typical clinical symptoms and showed radiological features of a SarsCov-2 infection.

Despite the ongoing COVID-19 pandemic, which delayed the implantation of the definitive prosthesis for a further 3 weeks and the patient's acute pulmonary distress [11], the periprosthetic infection was eradicated, which was in line with the guidelines in terms of both medical and surgical diagnosis and therapy. As a result, the patient was able to resume his normal daily activity.

\section{Abbreviations}

CT: Computer Tomography; GGO: Ground-glass opacification; CRP: C-reactive protein; ESR: Erythrocyte Sedimentation Rate; PJI: Periprosthetic Joint Infection

\section{Acknowledgements}

Not applicable.

\section{Authors' contributions}

All the authors have made substantial contributions to the conception, have approved the submitted version, agreed both to be personally accountable for the author's own contributions and to ensure the accuracy or integrity of any part of the work.

\section{Funding}

All the authors declare that they have no funding.

\section{Availability of data and materials}

The datasets analyzed during the current study are available from the corresponding author on reasonable request.

Ethics approval and consent to participate Not applicable.

\section{Consent for publication}

The patient gave his consent for publication.

\section{Competing interests}

All the authors declare that they have no competing interests.

Received: 27 July 2020 Accepted: 14 December 2020

Published online: 02 February 2021

\section{References}

1. Halim A, Grauer JN. Orthopedics in the era of COVID-19; 2020. 
2. Osmon DR, Berbari EF, Berendt AR, Lew D, Zimmerli W, Steckelberg JM, et al. Diagnosis and Management of Prosthetic Joint Infection: Clinical Practice Guidelines by the Infectious Diseases Society of Americaa. Diagnosis and Management of Prosthetic Joint Infection. 2013.

3. Chieffo G, Corsiac S, Rougereauc G, Enserd M, Eyrolled L, Kernéisa S, et al. Six-week antibiotic therapy after one-stage replacement arthroplasty for hip and knee periprosthetic joint infection. Med Mal Infect. 2020;50:567.

4. Shahpari O, Mousavian A, Elahpour N, Malahias MA, Ebrahimzadeh MH, Moradi A. The Use of Antibiotic Impregnated Cement Spacers in the Treatment of Infected Total Joint Replacement: Challenges and Achievements. Arch Bone Jt Surg. 2020;8(1):11-20. PMID: 32090140; PMCID: PMC7007713. https://doi.org/10.22038/abjs.2019.42018.2141.

5. Bayraktaroğlu S, Çinkooğlu A, Ceylan N, Savaş R. The novel coronavirus pneumonia (COVID-19): a pictorial review of chest CT features. Diagn Interv Radiol. 2020. https://doi.org/10.5152/dir.2020.20304

6. Beckman M, Nyrén S, Kistner A. A case-report of widespread pulmonary embolism in a middle-aged male seven weeks after asymptomatic suspected COVID 19 infection. Thromb J. 2020;18:19.

7. Yung $\mathrm{CS}$, Fok $\mathrm{KCH}$, Leung $\mathrm{CN}$, Wong $\mathrm{YW}$. What every orthopaedic surgeon should know about COVID-19: A review of the current literature. J Orthop Surg (Hong Kong). 2020;28(2):2309499020923499. PMID: 32406305. https:// doi.org/10.1177/2309499020923499.

8. Senthi S, Munro JT, Pitto RP. Infection in total hip replacement: metaanalysis. Int Orthop. 2011;35(2):253-60. Epub 2010 Nov 18. PMID: 21085957; PMCID: PMC3032119. https://doi.org/10.1007/s00264-010-1144-z. Epub 2010 Nov 18.

9. Tsukayama DTERGR. Infection after total hip arthroplasty. A study of one hundred and six infections. J Bone Joint Surg Am. 1996;78:512-23.

10. Garvin KL, Hanssen AD. Infection after total hip arthroplasty. Past, present, and future. J Boint Surgery Am. 1995;77:1576.

11. De Caro F, MH T, Verdonk P. Returning to orthopaedic business as usual after COVID-19: strategies and options. Knee Surg Sports Traumatol Arthrosc. 2020;28:1699.

\section{Publisher's Note}

Springer Nature remains neutral with regard to jurisdictional claims in published maps and institutional affiliations.

Ready to submit your research? Choose BMC and benefit from:

- fast, convenient online submission

- thorough peer review by experienced researchers in your field

- rapid publication on acceptance

- support for research data, including large and complex data types

- gold Open Access which fosters wider collaboration and increased citations

- maximum visibility for your research: over $100 \mathrm{M}$ website views per year

At $\mathrm{BMC}$, research is always in progress.

Learn more biomedcentral.com/submissions 